\title{
Why does the Antarctic Peninsula Warm in climate simulations?
}

\author{
Xin Qu • Alex Hall · Julien Boé
}

Received: 29 August 2010/Accepted: 30 April 2011

(C) Springer-Verlag 2011

\begin{abstract}
The Antarctic Peninsula has warmed significantly since the 1950s. This pronounced and isolated warming trend is collectively captured by 29 twentiethcentury climate hindcasts participating in the version 3 Coupled Model Intercomparison Project. To understand the factors driving warming trends in the hindcasts, we examine trends in Peninsula region's atmospheric heat budget in every simulation. We find that atmospheric latent heat release increases in nearly all hindcasts. These increases are generally anthropogenic in origin, and account for about $60 \%$ of the ensemble-mean warming trend in the Peninsula. They are driven primarily by wellunderstood features of the anthropogenic intensification of global hydrological cycle. As sea surface temperature increases, moisture contained in atmospheric flows increases. When such flows are forced to ascend the Peninsula's topography, enhanced local latent heat release results. The mechanism driving the warming of the Antarctic Peninsula is therefore clear in the models. Evidence for a similar mechanism operating in the real world is seen in the increasing snow accumulation rates inferred from ice cores drilled in the Peninsula. However, the relative importance of this mechanism and other processes previously identified as potentially causing the observed warming, such as the recent sea ice retreat in the Bellingshausen Sea, is difficult to assess. Thus the relevance of
\end{abstract}

X. Qu $(\bowtie) \cdot$ A. Hall · J. Boé

Department of Atmospheric and Oceanic Sciences,

University of California, PO BOX 951565,

Los Angeles, CA 90095-1565, USA

e-mail: xinqu@atmos.ucla.edu

Present Address:

J. Boé

CNRS/CERFACS, URA 1875, Toulouse, France the simulated warming mechanism to the observed warming is unclear, in spite of its robustness in the models.

Keywords Antarctic Peninsula · Warming . Latent heat transport

\section{Introduction}

Observations in the Southern Hemisphere high-latitudes reveal that the Antarctic Peninsula has warmed significantly since the 1950s (King 1994; Comiso 2000; Marshall et al. 2002; Vaughan et al. 2003; Turner et al. 2005; Chapman and Walsh 2007; Monaghan and Bromwich 2008; Turner et al. 2007; Orr et al. 2008). In some locations, the annual-mean warming trend may be as large as $0.5 \mathrm{~K} \mathrm{decade}^{-1}$. Successive losses of ice shelves on the Antarctic Peninsula (Vaughan and Doake 1996; Shepherd et al. 2003; Turner et al. 2005; Cook et al. 2005) may be among the dramatic impacts of the warming. Comparison with temperature variability simulated by climate models suggests the observed warming is at least partly anthropogenically-forced (Gillett et al. 2008). Nevertheless, anthropogenic warming in the rest of the Southern Hemisphere high-latitudes has not been unambiguously detected, especially in the interior of Antarctica continent where both warming and cooling trends have been reported (Thompson and Solomon 2002; Turner et al. 2006; Chapman and Walsh 2007; Steig et al. 2009).

The seemingly isolated warming in the Peninsula region is enigmatic, given the fact that anthropogenic forcings in the Southern Hemisphere high-latitudes, such as the increase in atmospheric greenhouse gas concentration, or depletion in the Southern Hemisphere stratospheric ozone, are largely uniform or at least zonally symmetric. Previous 
work has attributed the warming in part to the observed positive trend in the Southern Annular Mode (SAM), the dominant large-scale mode of atmospheric variability of the Southern Hemisphere extratropics (Thompson and Wallace 2000; Thompson and Solomon 2002; Gillett and Thompson 2003; Marshall 2007; Orr et al. 2008). The observed SAM trend may be forced by either an increase in atmospheric greenhouse gas concentration or depletion in the Southern Hemisphere stratospheric ozone or both (Arblaster and Meehl 2006; Cai and Cowan 2007). It has been hypothesized that during the SAM's positive phase, westerly flow in the Southern Hemisphere high-latitudes intensifies, enhancing atmospheric heat transport from the nearby ocean to the Peninsula and contributing to the observed warming. Warming could be further enhanced in the leeward slope of the Peninsula where the SAM trend induces a regional circulation shift from a "blocked" regime to a "flow-over" regime, leading to strong adiabatic warming (Marshall et al. 2006; van Lipzig et al. 2008; Orr et al. 2008). Nevertheless, there is clearly evidence suggesting that mechanisms other than the SAM trend may also contribute to the observed Peninsula warming. For example, a considerable portion of the observed warming is found to be unrelated to the SAM trend during austral summer and fall when the observed SAM trend is largest (Thompson and Solomon 2002), and the observed warming is greatest in austral winter when there is no significant SAM trend (Vaughan et al. 2003; Turner et al. 2005; Chapman and Walsh 2007; Marshall 2003). We note that the wintertime warming in the Peninsula has also been linked to the recent sea ice retreat in the Bellingshausen Sea (King 1994; van den Broeke 2000; Marshall et al.
2002), though the extent to which this relation is causal is not clear.

In this study we diagnose anthropogenic mechanisms affecting the thermal balance of the Antarctic Peninsula in the 29 twentieth century climate hindcasts done with 12 climate models (see Table 1 for details) participating in the version 3 Coupled Model Intercomparison Project (CMIP3). We do not analyze the mechanisms behind the observed warming directly in this study. (This is likely an impossible task given the lack of multi-decadal observations of the atmospheric state in this region.) However, over the period corresponding to the available instrumental record, the models collectively exhibit a pronounced and isolated warming trend in the Antarctic Peninsula (Fig. 1). The qualitative similarity to the observed distribution of Southern Hemisphere temperature change suggests the simulated mechanisms leading to warming in the Peninsula may be relevant to the real world. Moreover, the anthropogenic mechanisms seen in the models may indicate what processes are likely to generate future change in the region. The CMIP3 archive is also particularly valuable in our effort to diagnose specifically anthropogenic mechanisms because it contains output from pre-industrial control experiments with the same models used to perform the twentieth-century hindcasts. Comparison of the trends in the hindcasts to internally-generated trends in the control experiments allows anthropogenic influences in the hindcasts to be detected objectively.

To understand the factors driving warming trends in the hindcasts, we examine trends in Peninsula region's atmospheric heat budget in every simulation. We search for credible mechanisms of clearly anthropogenic origin that are qualitatively similar across the models. Our premise is

Table 1 Twenty nine Twentieth-century hindcasts with 12 CMIP3 climate models

\begin{tabular}{|c|c|c|c|c|c|c|}
\hline Number & Model & Hindcast & Resolution & "Warming" & "Nonwarming" & Ozone \\
\hline $1-2$ & CCSM3 & Runs 1-2 & $1.4^{\mathrm{o}} \times 1.4^{\mathrm{o}}$ & 1 & 2 & Yes \\
\hline $3-7$ & CGCM3.1(T47) & Runs $1-5$ & $3.8^{\mathrm{o}} \times 3.8^{\mathrm{o}}$ & $3-7$ & - & No \\
\hline 8 & CGCM3.1(T63) & Run 1 & $2.8^{\mathrm{o}} \times 2.8^{\mathrm{o}}$ & 8 & - & No \\
\hline 9 & CNRM-CM3 & Run 1 & $2.8^{\mathrm{o}} \times 2.8^{\mathrm{o}}$ & - & 9 & Yes \\
\hline 10 & CSIRO Mk3.5 & Run 1 & $1.9^{\mathrm{o}} \times 1.9^{\mathrm{o}}$ & 10 & - & Yes \\
\hline $11-13$ & ECHAM5/MPI-OM & Runs 1-3 & $1.9^{\mathrm{o}} \times 1.9^{\mathrm{o}}$ & $11-13$ & - & Yes \\
\hline $14-16$ & GFDL CM2.0 & Runs 1-3 & $2.0^{\mathrm{o}} \times 2.5^{\mathrm{o}}$ & 16 & $14-15$ & Yes \\
\hline $17-19$ & GFDL CM2.1 & Runs 1-3 & $2.0^{\mathrm{o}} \times 2.5^{\mathrm{o}}$ & 17 & $18-19$ & Yes \\
\hline 20 & IPSL CM4 & Run1 & $2.5^{\mathrm{o}} \times 3.8^{\mathrm{o}}$ & 20 & - & No \\
\hline $21-22$ & MIROC3.2(medres) & Runs $2-3$ & $2.8^{\mathrm{o}} \times 2.8^{\mathrm{o}}$ & - & $21-22$ & Yes \\
\hline $23-27$ & MRI CGCM2.3.2 & Runs 1-5 & $2.8^{\mathrm{o}} \times 2.8^{\mathrm{o}}$ & $25-27$ & $23-24$ & No \\
\hline $28-29$ & UKMO HadCM3 & Runs 1-2 & $2.5^{\mathrm{o}} \times 3.8^{\mathrm{o}}$ & $28-29$ & - & Yes \\
\hline
\end{tabular}

(1st column) The reference numbers of the hindcasts. (2nd column) The names of the models. (3rd column) The original numbers of the hindcasts. (4th column) The mean horizontal resolutions of the models. (5-6th columns) The hindcasts are classified into "warming" and "nonwarming", depending on whether the Antarctic Peninsula exhibits anthropogenic warming trends over the period 1958-2000 (see text in Sect. 2) (7th column) The hindcasts are identified according to whether they account for depletion in the Southern Hemisphere stratospheric ozone 
Fig. 1 Geographic distributions of annual-mean surface temperature trend over the period 1958-2000 in the Southern Hemisphere extratropics in a observations, b all hindcasts, c 19 "warming" hindcasts and $\mathbf{d} 10$

"nonwarming" hindcasts (see Table 1). Surface air and sea surface temperature are used in trend calculations for land and oceanic locations, respectively. The land area within the black box $\left(55^{\circ}-80^{\circ} \mathrm{W}, 62^{\circ}-77^{\circ} \mathrm{S}\right)$ in a is used to construct regionalmean trends of temperature and heat fluxes in the Antarctic Peninsula throughout this paper

\section{Temperature trends}
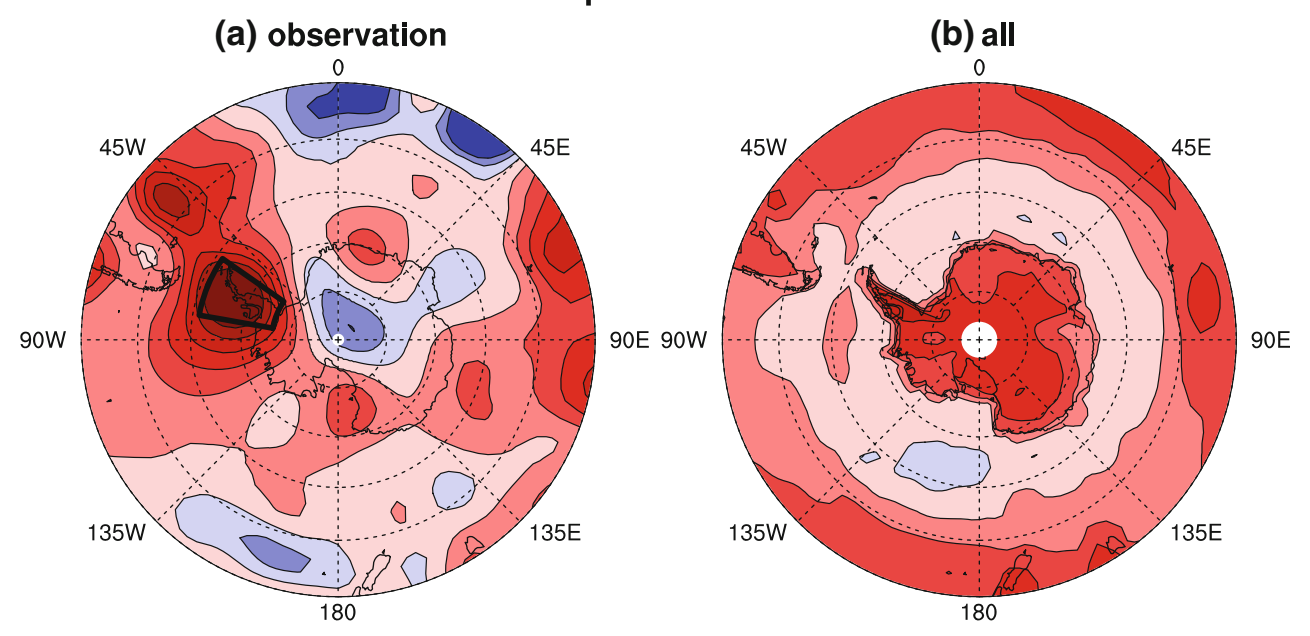

(c) warming

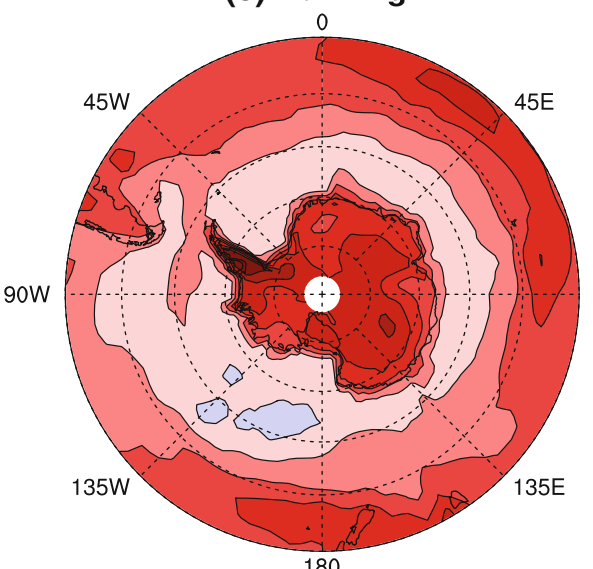

(d) nonwarming
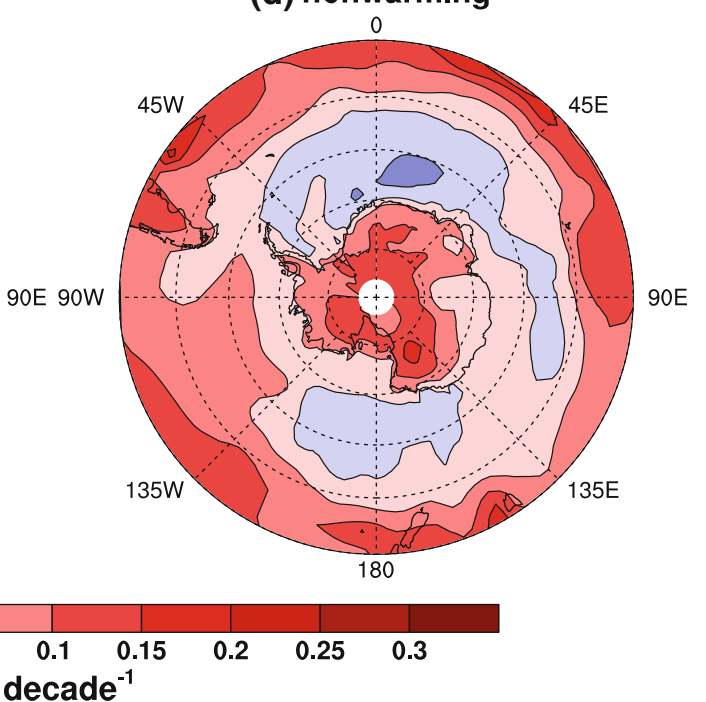

that model agreement signifies a high degree of scientific credibility when associated with common, physically plausible processes. It turns out that atmospheric latent heat release in Peninsula region increases in nearly all hindcasts, and emerges as a dominant heat source for warming trends in the hindcasts. These increases are largely driven by welldocumented and well-understood anthropogenic increases in poleward moisture transports associated with the intensification of global hydrological cycle (Manabe et al. 1990; Alexeev et al. 2005; Held and Soden 2006; Cai and Lu 2007; references therein).

Our analysis has been done with both annual- and seasonal-mean data, and results from both analyses turn out to be largely consistent. For this reason and also for clarity, only the annual-mean analysis is discussed in detail below. For completeness, though, we will touch on seasonal variations. The study is presented as follows: Data and methodology are described in Sect. 2, followed by discussions of temperature trends in Sect. 3 and heat flux trends in Sect. 4. The potential linkage of simulated latent heat trends and SAM trends is discussed in Sect. 5. In Sect. 6 , because of their central role in the warming of the Peninsula, we examine factors modulating simulated latent heat trends. Summary and implications are given in Sect. 7. Relevant information on pre-industrial control experiments is included in the Appendix.

\section{Data and methodology}

Simulated climate is examined in 29 twentieth-century simulations done with 12 CMIP3 models (see Table 1). In these simulations, historical twentieth-century forcing was imposed. (Though both natural forcing such as volcanic eruptions and variations in solar irradiance and anthropogenic forcing are applied, simulated twentieth-century 
climate change is likely dominated by anthropogenic forcing rather than natural forcing; Forster et al. 2007.) Twentieth-century hindcasts done with 11 other CMIP3 models are available too, but they are not used in this study for several reasons: (1) Pre-industrial control simulations done with 5 of these models (BCCR-BCM2.0, GISS-AOM, INGV-SXG, INM-CM3.0 and MIROC3.2(hires)) do not provide long enough time series (less than 340 years) to calculate stable statistics of internally-generated climate variability, (2) 5 other models (CSIRO-Mk3.0, ECHO-G, GISS-EH, GISS-ER and PCM) do not provide all variables necessary for our analysis and (3) one model, FGOALSg1.0, exhibits serious biases in the simulated high-latitude climate variability. (For example, it has nearly permanent sea ice out to $60^{\circ} \mathrm{S}$; Russell et al. 2006.) We focus on the period 1958-2000, a 43-year time span. The first year in our analysis period, 1958, was an International Geophysical Year, and marks the beginning of a more robust instrumental record in the Peninsula. Indeed, most observational studies begin their analyses of Peninsula warming trends with the late 1950s. The hindcasts end in 2000. Some of these simulations were continued under an anthropogenic forcing scenario until the end of the twentieth-first century. However, since this is a future forcing scenario rather than an historical forcing, the simulated anthropogenic responses after 2000 may not be directly comparable to observations. For this reason we end our analysis period with the year 2000 .

The trend in surface temperature for the period 1958-2000 is first computed for each location in the Southern Hemisphere mid-to-high latitudes and for every twentieth-century hindcast. We then average the trend over the Peninsula (land areas within the black box in Fig. 1a, a definition used hereafter). To detect anthropogenic warming signatures in the region, we compare the magnitude of the spatially-averaged trend to those of simulated internally-generated trends in all consecutive 43 -year periods in the accompanying pre-industrial control experiment done with the same model. If less than $5 \%$ of simulated internal trends exceed the hindcasted trend, then the hindcasted trend is considered at least partly anthropogenically-forced. Otherwise, the hindcasted trend is considered to be internally generated. Hindcasts with detectable anthropogenic warming in the Peninsula are referred to as "warming" hindcasts hereafter, while hindcasts without are referred to as "nonwarming" hindcasts. Using this criterion, we identify 19 "warming" and 10 "nonwarming" hindcasts (see Table 1). Visual inspection of the 5-6th columns of Table 1 reveals that hindcasts done with the same model may fall into different categories occasionally. This is to be expected since the detectability of anthropogenic climate change is affected by the phasing of internally-generated climate variability. For example, internally-generated cooling trends may counteract anthropogenic warming trends, delaying the detectability of anthropogenic climate change in "nonwarming" hindcasts. Thus the failure of any particular "nonwarming" simulation to simulate warming in the Peninsula does not necessarily imply that simulation does not simulate anthropogenic mechanisms generating warming in the Peninsula. For this reason we use all hindcasts including the "nonwarming" hindcasts in our heat budget analysis described below.

To disentangle the factors driving temperature trends, we construct a time series of changes in the atmospheric heat budget in the simulations. We represent the change in the heat budget within a single year (or a single season) at each location as:

$C_{p} \Delta \widetilde{T}=L H+S H+S W+L W+S F$

where $\Delta \widetilde{T}$ is the change in vertically-integrated and massweighted tropospheric (from the surface to $300 \mathrm{hPa}$ ) temperature between the first and last days of each year (Jan. 1 and Dec. 31) or each season (i.e., Jun. 1 and Aug. 31 in case of austral winter), and $C_{p}$ is the heat capacity of air. (Since daily data is generally not available in the CMIP3 archive, daily $\widetilde{T}$ is obtained by interpolating monthly $\widetilde{T}$ of the associated two consecutive months.) $L H, S H, S W, L W$ and $S F$ are, respectively: the convergence of verticallyintegrated atmospheric latent heat transport, convergence of vertically-integrated atmospheric sensible heat transport, top-of-the-atmosphere (TOA) net shortwave radiation flux, TOA net longwave radiation flux and net surface heat flux. $L H$ is evaluated by $(P-E) \cdot L$, where $P, E$ and $L$ are precipitation, evaporation and latent heat of condensation, respectively. Note that the latent heat of fusion is included in the value of latent heat of condensation used here, under the assumption that precipitation in the Peninsula overwhelmingly takes the form of snow. $S W, L W$ and $S F$ are evaluated from TOA radiation fluxes, surface radiation fluxes, and surface sensible and latent heat fluxes, all available directly from the simulations.

It is impossible to evaluate $S H$ directly since the daily data needed to do so is not available in the CMIP3 archive for most simulations. Here we evaluate it as the residual between $C_{p} \Delta \widetilde{T}$ and the sum of $L H, S W, L W$ and $S F$. This approach based on energy conservation is valid because there are virtually no errors in the estimates of $L H, S W, L W$ and $S F$. Interpolation may introduce errors in the estimates of daily $\widetilde{T}$. But, since the product of $C_{p}$ and $\Delta \widetilde{T}$, the term on the left side of Eq. 1, is typically 2 orders of magnitude smaller than the other terms in the equation, they are unlikely to introduce significant errors into the estimates of SH.

Our sign convention is that positively- (negatively-) signed heat flux corresponds to heating (cooling) of the 
atmosphere. We note that since $C_{p} \Delta \widetilde{T}$ is typically very small, the yearly temperature change is determined by competition among warming and cooling heat flux anomalies nearly equal in magnitude. A warming trend arises when the heat flux anomalies causing warming increase steadily from year to year, and consistently win the competition with the heat flux anomalies causing cooling.

Once the heat budget change and its components are calculated for each year, trends in these quantities can be calculated. We then average the trends over the Peninsula. Trends with a positive sign sustain warming or counteract long-term cooling in the Peninsula, while those with a negative sign have the opposite effect. The same criterion used to determine whether temperature trends have an anthropogenic component is applied to the time series of heat budget components to determine whether they are anthropogenically-forced. Since surface temperature is more frequently measured than temperature aloft, we use surface temperature rather than $\widetilde{T}$ in all our analysis except for estimating $S H$ to facilitate model/observation comparison. Our analysis is not particularly sensitive to the choice of temperature variable as temperature trends are largely coherent within the troposphere (Fig. 2).

A SAM index proposed by Gong and Wang (1999) is used here to quantify simulated SAM variability and trends. It is defined as the difference in normalized zonalmean sea level pressure between $40^{\circ}$ and $65^{\circ} \mathrm{S}$. The use of

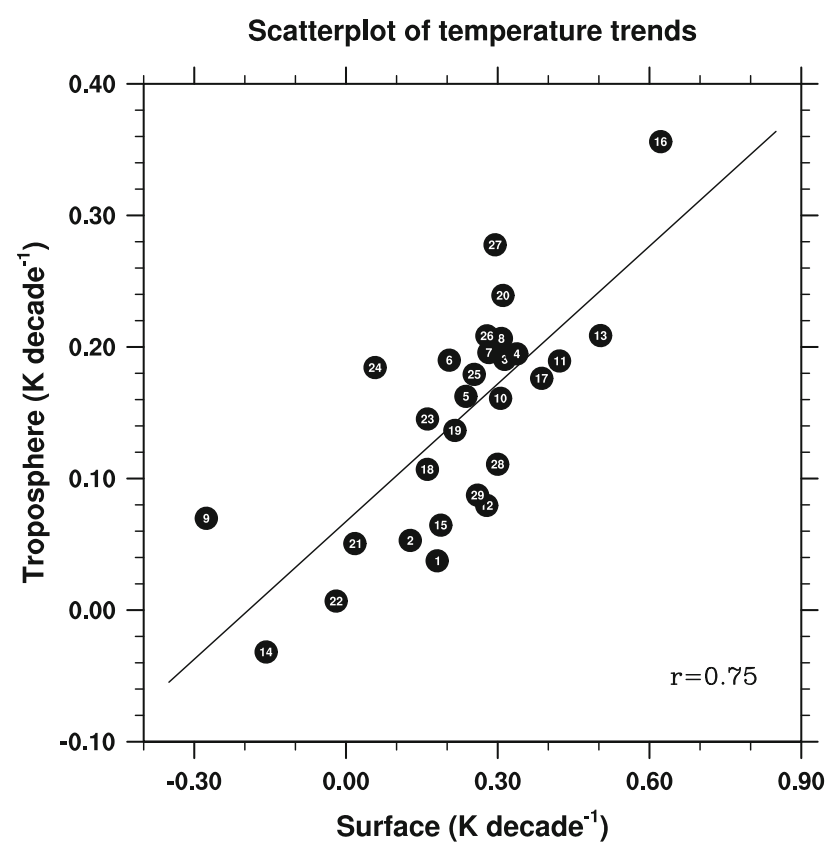

Fig. 2 Scatterplot of the vertically-integrated, mass-weighted and annual-mean tropospheric temperature trend against annual-mean surface temperature trend in the Peninsula in 29 simulations. A leastsquares fit regression line is shown as the diagonal. The number of each simulation is also shown this definition facilitates the model/observation comparison as it has been used in previous observational SAM analyses (i.e., Marshall 2003). Note that this index is almost perfectly correlated with an alternative definition using the time series associated with the first empirical orthogonal function of sea level pressure anomalies south of $20^{\circ} \mathrm{S}$ in all models.

Two observational surface temperature data sets are used here to validate hindcasts. One is compiled by Chapman and Walsh (2007, referred to as CW hearafter) from station, ship and buoy observations. It covers the area south of $40^{\circ} \mathrm{S}$ and provides surface air temperature over land and sea surface tempeature over ocean on a $1^{\circ} \times 1^{\circ}$ grid. As noted above, we extract the same quantities from hindcasts to facilitate model/observation comparison. The other is reconstructed by Monaghan et al. (2008a, referred to as MBCC) based on station observations archived in the Reference Antarctic Data for Environmental Research database (Turner et al. 2004). It covers only the Antarctic continent and is also provided on a $1^{\circ} \times 1^{\circ}$ grid. The two data sets differ in the way of interpolating data where there are no observations. Chapman and Walsh (2007) use natural neighbor interpolation, while Monaghan et al. (2008a) use the spatial relationships established by a numerical model. Fortunately, this difference does not introduce a significant inconsistency in estimates of the warming trend in the Peninsula region (Table 2).

\section{Temperature trends}

Figure 1a shows the geographic distribution of observed annual-mean temperature trends in the Southern Hemisphere mid-to-high latitudes based on the $\mathrm{CW}$ data set. Maximum warming occurs in the Peninsula and nearby ocean. The regionally-averaged temperature trend in the Peninsula is $0.31 \mathrm{~K} \mathrm{decade}^{-1}$ (Table 2). A similar trend is also obtained based on the MBCC data set. Significant

Table 2 Observed trends $\left(\mathrm{K} \mathrm{decade}^{-1}\right)$ in the regionally-averaged surface temperature in the Antarctic Peninsula and associated 95\% confidence limits based on (1st column) the $\mathrm{CW}$ and (2nd column) MBCC data sets

\begin{tabular}{llll}
\hline & CW & MBCC & Simulations \\
\hline Annual & $0.31 \pm 0.15$ & $0.32 \pm 0.24$ & $0.23 \pm 0.30$ \\
DJF & $0.16 \pm 0.04$ & $0.21 \pm 0.14$ & $0.16 \pm 0.20$ \\
MAM & $0.37 \pm 0.20$ & $0.71 \pm 0.42$ & $0.30 \pm 0.49$ \\
JJA & $0.59 \pm 0.74$ & $0.69 \pm 0.60$ & $0.25 \pm 0.58$ \\
SON & $0.11 \pm 0.31$ & $0.10 \pm 0.38$ & $0.20 \pm 0.35$ \\
\hline
\end{tabular}

(3rd column) Ensemble-mean surface temperature trends $\left(\mathrm{K}_{\text {decade }}{ }^{-1}\right)$ and the 5 and 95 percentiles of simulated temperature trends. Both seasonal- and annual-mean values are given in the table 
warming also occurs in oceanic areas to the north of the Peninsula, centered a few hundred km northeast of Falkland Islands with a magnitude of about $0.25 \mathrm{~K} \mathrm{decade}^{-1}$. The rest of the region exhibits either small warming or cooling. The geographic distribution of the ensemble- and annual-mean temperature trend in all hindcasts is shown in Fig. 1b. Simulated warming is enhanced over the Antarctic Peninsula, in rough agreement with observations. Nevertheless, the hindcasts as an ensemble slightly underestimate warming in the Peninsula. The ensemble-mean regional warming is only $0.23 \mathrm{~K} \mathrm{decade}^{-1}$, about $30 \%$ smaller than the observed (Table 2). The underestimation of the observed warming trend by hindcasts is even more obvious in the ocean near the Peninsula. The observed trend there can reach $0.35 \mathrm{~K} \mathrm{decade}^{-1}$ or higher, while the ensemblemean trend is barely $0.1 \mathrm{~K}$ decade $^{-1}$. The observed oceanic warming is likely associated with recent sea ice retreat in the Bellingshausen Sea. Thus this underestimation may be an indication that hindcasts as an ensemble do not simulate a sea-ice retreat comparable to observations.

Comparison of the patterns of temperature trend in Fig. $1 \mathrm{a}, \mathrm{b}$ reveals that the ensemble-mean warming is much more uniform than the observed warming. One way to reconcile this inconsistency is that while observed warming may be a mix of internally-generated climate variability and anthropogenic climate change, the ensemble-mean warming is likely dominated by anthropogenic climate change. Anthropogenic climate change is likely more uniform than internally-generated climate variability.

The geographical distribution of the ensemble- and annual-mean temperature trend in the 19 "warming" simulations is shown in Fig. 1c. Not surprisingly, the ensemble-mean warming trend in the Peninsula in these hindcasts is much greater than the ensemble-mean of all hindcasts, and thus in better agreement with observations. Nevertheless, the difference in the ocean near the Peninsula remains.

The distribution of the ensemble- and annual-mean temperature trends in the "nonwarming" experiments is shown in Fig. 1d. These experiments exhibit a different pattern of temperature change throughout the Southern Hemisphere high-latitudes than their "warming" counterparts. They show some warming in the interior of Antarctica, but little in the Antarctic Peninsula, and even exhibit cooling in much of the Southern Ocean, especially near the Weddell and Ross Seas. A closer inspection of temperature time series averaged over the Weddell and Ross Seas in the "nonwarming" experiments (not shown) reveals that the oceanic cooling trends of Fig. 1d are very likely the signature of internally-generated variability of decadal or longer time scale. This is confirmed by a significance test of the oceanic trends against internal climate variability in the corresponding control experiments. These internally-generated cooling trends probably counteract anthropogenic warming in the Antarctic Peninsula through horizontal temperature advection, resulting in generally smaller Peninsula warming seen in Fig. 1d.

The observed warming in the Peninsula shows a clear seasonal dependence (King 1994; Comiso 2000; Marshall et al. 2002; Vaughan et al. 2003; Turner et al. 2005; Chapman and Walsh 2007; Monaghan and Bromwich 2008; Orr et al. 2008), though warming occurs in all seasons. The Peninsula temperature trend in austral fall (MAM) and winter (JJA) is larger than that in spring (SON) and summer (DJF). This is true for both CW- and MBCCbased estimates. Note that the MAM temperature trend based on the MBCC data set is almost twice that based on the $\mathrm{CW}$ data set, an inconsistency likely attributable to differences in their interpolation methods, discussed above. The ensemble-mean temperature trend also exhibits similar seasonal variations, albeit somewhat smaller than observations.

Intermodel variations in simulated Peninsula temperature trends are represented by the 5 and 95 percentiles shown in Table 2 . These variations may stem partly from differences in the phasing of internal variability. We note that model/observation differences in temperature trends are generally much smaller than either intermodel variations in temperature trends or statistical uncertainties in the estimates of observed trends, represented by the $95 \%$ confidence limits. Thus the observed record of climate change in the Peninsula region is well within the range of possible outcomes captured by the ensemble of hindcasts.

\section{Heat flux trends}

To understand the factors driving simulated warming trends in the Peninsula, we examine simulated heat flux trends in this section. The ensemble- and annual-mean $L H, L W, S F, S W$ and $S H$ trends in the Peninsula are $0.86,0.09,-0.13,-0.27$ and $-0.55 \mathrm{~W} \mathrm{~m}^{-2}$ decade $^{-1}$, respectively (Table 3). Thus $L H$ and $L W$ trends generally contribute to warming, with the former being overwhelmingly dominant, while the $S F, S W$ and $S H$ trends lead to

Table 3 Ensemble-mean trends $\left(\mathrm{W} \mathrm{m}^{-2}\right.$ decade $\left.^{-1}\right)$ in the regionallyaveraged $L H, L W, S F, S W$ and $S H$ in the Peninsula

\begin{tabular}{llrrrl}
\hline & $L H$ & \multicolumn{1}{l}{$L W$} & \multicolumn{1}{l}{$S F$} & \multicolumn{1}{l}{$S W$} & \multicolumn{1}{l}{$S H$} \\
\hline Annual & 0.86 & 0.09 & -0.13 & -0.27 & -0.55 \\
DJF & 0.88 & 0.37 & -0.19 & -0.46 & -0.60 \\
MAM & 1.19 & 0.01 & -0.27 & -0.02 & -0.91 \\
JJA & 0.56 & -0.12 & 0.09 & -0.02 & -0.51 \\
SON & 0.81 & 0.11 & -0.17 & -0.56 & -0.19 \\
\hline
\end{tabular}

Both seasonal- and annual-mean values are given in the table 
cooling in the region, with the $S H$ trend being most important. Regionally-averaged and annual-mean trends in $L H, L W, S F, S W$ and $S H$ fluxes in the Peninsula are shown for each simulation in Fig. 3, segregated by "warming" and "nonwarming" experiments. A overview of signs and magnitudes of the trends as well as the detectability of an anthropogenic component within them is given in Table 4 .

\subsection{Trends causing warming}

Since we are concerned with the causes of simulated warming in the Peninsula, we first examine the heat flux trends leading to warming. We find the $L H$ trend acts to warm the Peninsula in 26 hindcasts, including most "nonwarming" hindcasts, while the warming effect of other trends is seen much less consistently. Comparison of the trend magnitudes in each hindcast reveals that the $L H$ trend is the dominant positive trend in $79 \%$ of the hindcasts. Finally, an anthropogenically-generated positive $L H$ trend is detected in about half the simulations, much more often than other trends. Even of the ten simulations that do not exhibit detectable anthropogenic warming, two exhibit positive $L H$ trends of anthropogenic origin (Fig. 3b). In short, the $L H$ trend emerges as distinct from the other flux trends potentially affecting the Peninsula's thermal balance in the positive sense. It is positive in nearly all hindcasts, it is typically larger than the other trends, and it often has a detectable anthropogenic component. We note that $L H$ trends are also a dominant contributor to warming in the Peninsula in all seasons (Table 3).

While the focus of this section is mainly on the origin of the overwhelmingly dominant positive $L H$ trends, for the sake of completeness we briefly discuss the origin of the generally positive $L W$ trends. The $L W$ trends include effects from both radiative forcing (resulting from anthropogenic increase in atmospheric greenhouse gas concentration) and

Table 4 (1st column) The percent of simulations in which each of the regionally-averaged and annual-mean $L H, L W, S F, S W$ and $S H$ trends in the Antarctic Peninsula is positive (negative)

\begin{tabular}{llll}
\hline & $\begin{array}{l}\text { Positive } \\
\text { (negative) }\end{array}$ & $\begin{array}{l}\text { Dominant } \\
\text { positive (negative) }\end{array}$ & $\begin{array}{l}\text { Positive } \\
\text { (negative) and } \\
\text { anthropogenically-forced }\end{array}$ \\
\hline$L H$ & $90(10)$ & $79(3)$ & $45(0)$ \\
$L W$ & $59(41)$ & $10(10)$ & $24(7)$ \\
$S F$ & $24(76)$ & $0(0)$ & $3(34)$ \\
$S W$ & $21(79)$ & $0(14)$ & $0(55)$ \\
$S H$ & $21(79)$ & $10(62)$ & $3(24)$ \\
\hline
\end{tabular}

(2nd column) The percent of simulations in which each of the five heat flux trends is not only positive (negative), but also greater than other positive (negative) trends in magnitude. (3nd column) The percent of simulations in which each of the five heat flux trends is not only positive (negative), but also has an anthropogenic component
$L W$ radiative feedbacks. To separate these two effects, we estimated the radiative forcing in the Peninsula for the 1958-2000 period. Unfortunately, the forcing is only available for one model (IPSL CM4), being about 0.17 $\mathrm{W} \mathrm{m}{ }^{-2}$ decade $^{-1}$ averaged over the Peninsula. Assuming this is a reasonable estimate of the forcing for all simulations, the effect of $L W$ radiative feedbacks on the $L W$ trend can be approximated by subtracting the $L W$ trend from this value. We find that $62 \%$ of the hindcasts exhibit a small negative $L W$ trend after the effect of radiative forcing is removed (not shown). This suggests that the warming effect of the $L W$ trend is largely due to radiative forcing and any remaining $L W$ radiative feedback effects generally lead to cooling. In any case, the warming effect of radiative forcing trend is dwarfed by the typical $L H$ trend, so that any simulated warming seen in the Peninsula is generally impossible to understand in terms of radiative forcing alone.

It is possible to quantify the contribution of $L H$ trend to the Peninsula temperature trend by multiplying the magnitude of each $L H$ trend with a coefficient representing the magnitude of the temperature anomaly induced by a unit change in $L H$. This coefficient can be calculated based on the pre-industrial experiments by regressing each temperature time series onto the respective $L H$ time series. Using this method, we estimate the ensemble- and annual-mean

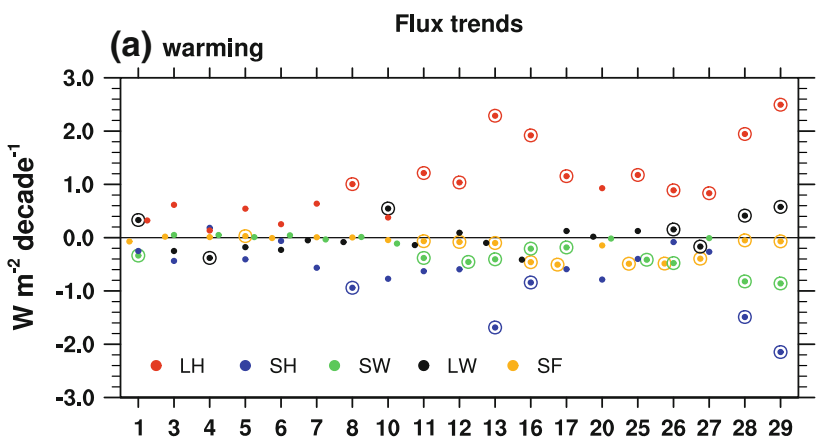

(b) nonwarming

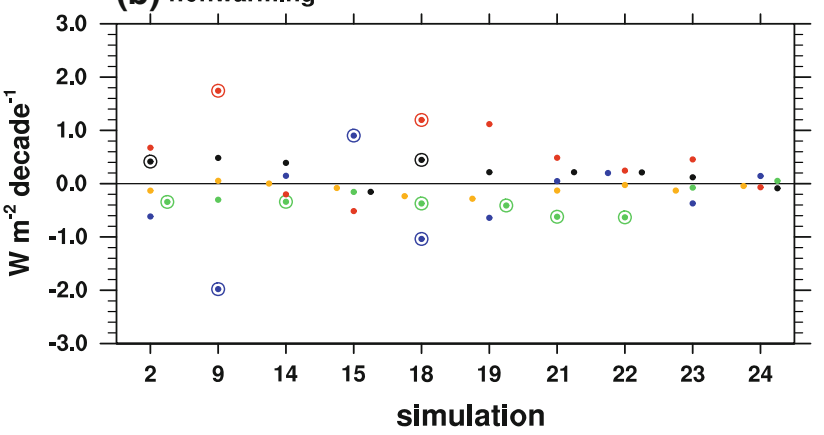

Fig. 3 Regionally-averaged and annual-mean trends in latent heat transport ( $\mathrm{LH}$, red), sensible heat transport ( $\mathrm{SH}$, blue), top-of-theatmosphere net shortwave radiation (SW, green) and net longwave radiation (LW, black) and net surface flux (SF, yellow) in the Peninsula for a 19 "warming" hindcasts and b 10 "nonwarming" hindcasts. Circles represent trends with an anthropogenic component 
temperature trend induced by the $L H$ trend is $0.13 \mathrm{~K}$ decade $^{-1}$. Thus approximately $60 \%$ of the overall ensemblemean warming in the Peninsula can be attributed to the $L H$ trend. The remaining $40 \%$ may be induced by the anthropogenic forcing itself.

Insight into the origin of the large and robust positive $L H$ trends may be found in their ensemble-mean geographic distribution (Fig. 4). The trend is largely zonally symmetric and generally positive in the Southern Ocean, while negative further north. This pattern implies an increase in poleward latent heat transport from roughly $50^{\circ} \mathrm{S}$ to $70^{\circ} \mathrm{S}$. This is consistent with robust and wellknown features of the anthropogenic intensification of the global hydrological cycle (Manabe et al. 1990; Alexeev et al. 2005; Held and Soden 2006; Cai and Lu 2007; references therein). We note that a positive SAM trend could also induce a pattern of $L H$ trend similar to Fig. 4 . But, as discussed in Sect. 5 below, the magnitudes of the $L H$ trends induced by simulated SAM trends are generally much smaller than those in Fig. 4. Another noticeable feature of Fig. 4 is the significantly larger positive values in the Peninsula region than the rest of Antarctica. This regional enhancement of poleward $L H$ transport may occur because the Peninsula protrudes northward into the latitude belt where $L H$ transport increases. Orographically-induced condensation, as moister flows predominantly from the northwest are forced up the Peninsula's western side, likely

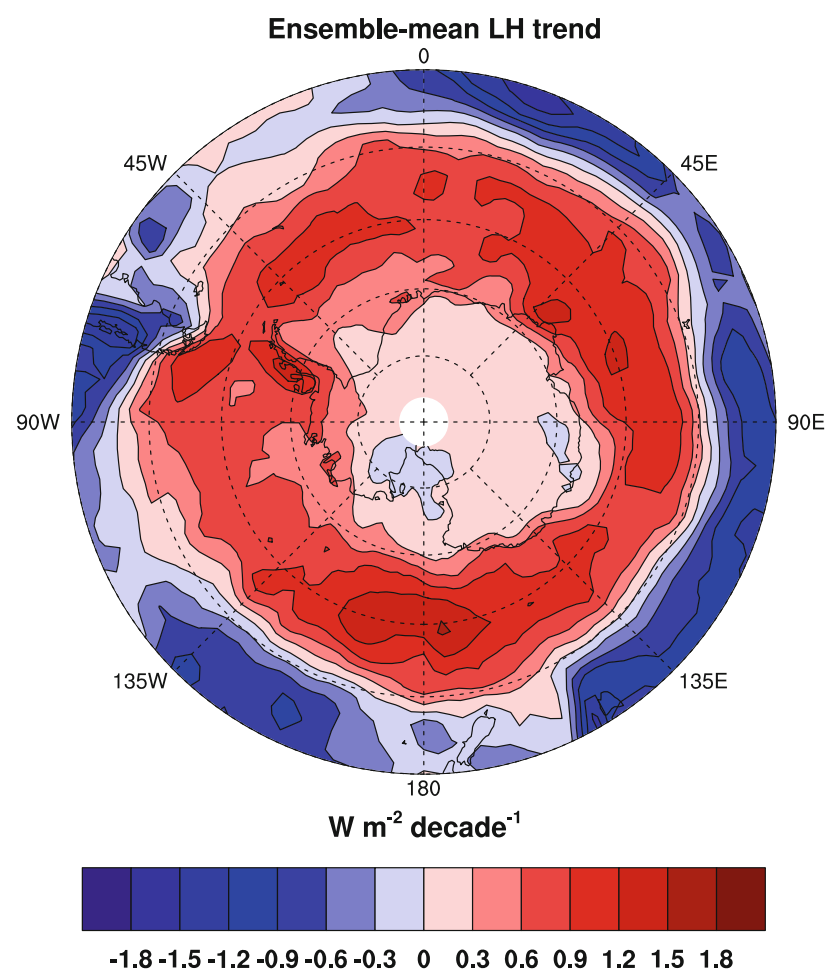

Fig. 4 Geographic distribution of the ensemble- and annual-mean trend in latent heat transport in 29 hindcasts also contributes to the enhancement. Evidence of this effect may be seen in the excess $L H$ trends west of Peninsula's central spine. The local maximum in $L H$ trends may also be displaced to the Peninsula's west because of orographic blocking of atmospheric flows, forcing ascent and condensation in advance of the land mass itself. This effect has been shown to be important in a climatological sense in other coastal regions (Jiang 2003; Neiman et al. 2004; Galewsky 2008; Hughes et al. 2009). Since the ensemblemean warming in 29 hindcasts is also enhanced over the Antarctic Peninsula (Fig. 1), the match of this pattern to the noticeable enhancement of the $L H$ trends over the Peninsula is further evidence that in an ensemble-mean sense simulated Peninsula warming arises mostly from the $L H$ increase. Warming in and around the Peninsula may be somewhat less concentrated geographically than the $L H$ trend because of lateral redistribution of heat by atmospheric motions.

Though the $L H$ trend in the rest of Antarctica is generally much smaller than that in the Peninsula (Fig. 4), it turns out to be a dominant contributor to the continentalscale warming seen in Fig. 1b. As show in Table 5, the ensemble- and annual-mean $L H$ trends averaged in the Antarctic continent excluding the Peninsula is positive and larger than other positive trends such as the $S H$ trend. The regionally-averaged radiative forcing, estimated to be $0.12 \mathrm{~W} \mathrm{~m}^{-2}$ decade $^{-1}$, is also smaller than the $L H$ trend. It is worth pointing out that our finding here is not inconsistent with previous work suggesting that simulated warming in Antarctica is strongly correlated with simulated increase in downward longwave radiation at the surface (DLWS, Monaghan et al. 2008b). Simulated DLWS increase may stem from (1) the increase in the effective emissivity of the atmosphere due to an increase in atmospheric greenhouse gas concentration, the very effect represented by radiative forcing and (2) atmospheric warming induced by other processes such as the $L H$ increase. In fact, we find that the $D L W S$ trend is strongly correlated with the $L H$ trend across hindcasts (the correlation coefficient is 0.75), an important line of evidence that the $L H$ increase may significantly contribute to the increase in DLWS.

The Southern Ocean region also generally exhibits a large increase in poleward $L H$ transport in hindcasts (Fig. 4). However, this has a negligible effect on sea surface temperature because of system's large effective heat capacity here, a well-known feature of transient climate

Table 5 Ensemble- and annual-mean trends $\left(\mathrm{W} \mathrm{m}^{-2}\right.$ decade $\left.^{-1}\right)$ in $L H, L W, S F, S W$ and $S H$ averaged over the Antarctic continent excluding the Antarctica Peninsula

\begin{tabular}{llllll}
\hline & $L H$ & $L W$ & $S F$ & $S W$ & $S H$ \\
\hline Annual & 0.15 & -0.00 & -0.02 & -0.20 & 0.07 \\
\hline
\end{tabular}


change. For example, when we examine the models' atmospheric heat budgets in the Southern Ocean region, we find that the increase in $L H$ transport is primarily compensated by a decrease in net upward surface heat flux (not shown). The accompanying increase in oceanic heat storage is then effectively distributed over a large enough portion of the water column to prevent any appreciable surface warming.

The intermodel variability in the $L H$ flux trend seen in Fig. 3 provides an opportunity to examine the mechanistic link between the $L H$ flux trend and the temperature response of the Southern Hemisphere further. If increased $L H$ fluxes really are responsible for simulated warming in the Peninsula, models with larger increases in $L H$ fluxes ought to warm more. We test this hypothesis by correlating $L H$ trends with temperature trends across the 29 simulations at each location. The relationship between $L H$ and temperature trends is strikingly different over Antarctica and the surrounding oceans (Fig. 5). The warming effect of increased $L H$ transport into the Peninsula is clearly supported by the large and statistically significant positive correlation between the $L H$ and temperature trends there. Significant positive correlation is also seen in much of the rest of Antarctica, suggesting increased $L H$ transport controls the magnitude of warming there as well, likely by
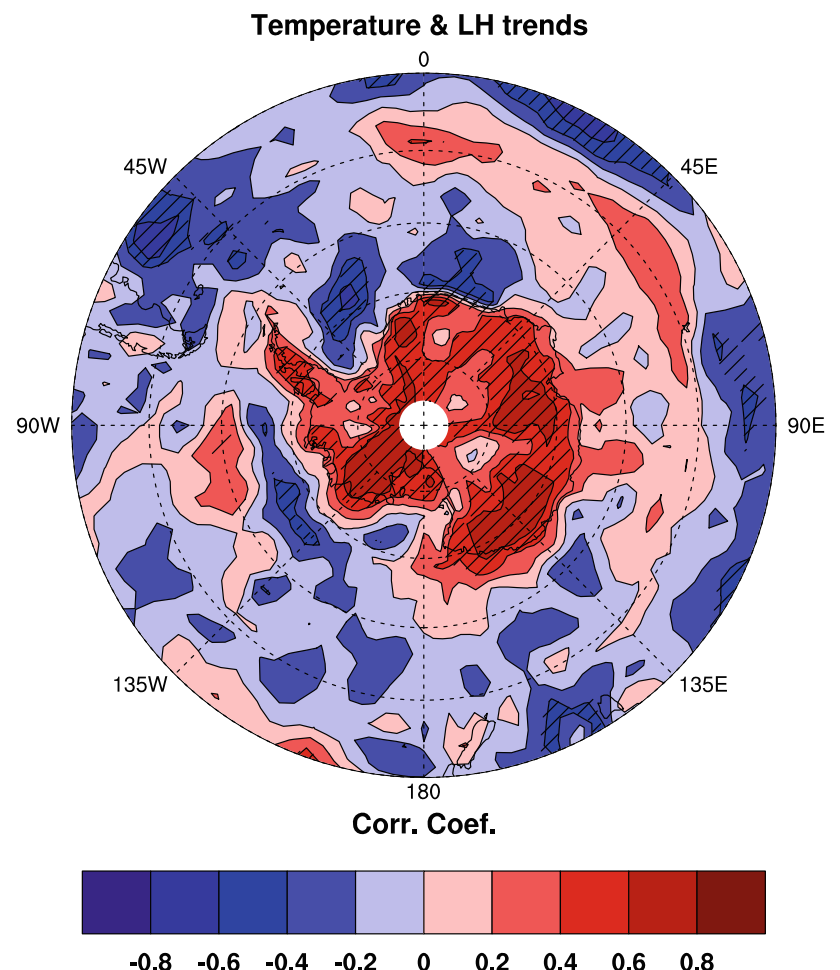

Fig. 5 Geographic distribution of correlation between annual-mean trends in temperature and those in latent heat transport across 29 hindcasts. Correlation with the significance level above $95 \%$ is shaded increasing downward longwave radiation at the surface (Fig. 1). Nevertheless, warming there is generally smaller than in the Peninsula region, consistent with typically much smaller $L H$ trends in the rest of Antarctica (Fig. 4). The correlations in oceanic areas are usually negative, likely due to the fact that warming of the sea surface favors an increase in evaporation.

\subsection{Trends causing cooling}

The analysis of the previous section demonstrates that simulated warming in the Antarctic Peninsula is generally caused by an increase in latent heat transport due to an intensifying global hydrological cycle. Next we examine the origins of heat flux trends counteracting the warming of the region.

Based on the ensemble- and annual-mean figures, about $42 \%$ of the heat gained from the $L H$ and $L W$ increases is compensated by the combined $S F$ and $S W$ reductions, while the remaining $58 \%$ is compensated by the $S H$ reduction. The $S H$ reduction thus emerges as the dominant cooling mechanism in the Peninsula. This reduction in sensible heat flux into the Peninsula region may simply arise from the fact that simulated warming is enhanced in the Peninsula, leading to a thermal damping of the local temperature anomaly. As shown in Fig. 1, the Peninsula generally warms more than the surrounding ocean, reducing the thermal contrast between the two areas. Assuming the diffusive effects of regional atmospheric circulation are largely unchanged over the course of the hindcasts, this will result in a reduction of $S H$.

The reduction of $S H$ is the dominant cooling mechanism in the Peninsula not only in the ensemble-mean, but also in most individual simulations. The magnitudes of $\mathrm{SH}$ trends are larger than those of other negative trends in $62 \%$ of the simulations (Table 4). Strong evidence that the $S H$ trend can be viewed as the signature of a thermal damping process is the very strong anti-correlation between $\mathrm{LH}$ and $\mathrm{SH}$ trends across simulations (the correlation coefficient is -0.90 , Fig. 6). Simulations with a larger $L H$ increase nearly always exhibit a relatively large $S H$ reduction. The most straightforward way to interpret this anti-correlation is that the $S H$ is responding to the $L H$ increase. The fact that the $S H$ trends tend to be somewhat smaller in magnitude than the $L H$ trends is also consistent with the idea that the $S H$ cooling is the damping response to the $L H$-driven warming. The $L H$ increase can be viewed as a non-radiative anthropogenic forcing arising from the intensification of the hydrological cycle, and the $S H$ reduction as a response to the resulting warming. In this sense, it is a negative feedback, restoring the region's thermal balance. No such tight relationship exists between the $L H$ and other flux trends typically causing cooling such as $S F$ and $S W$. 


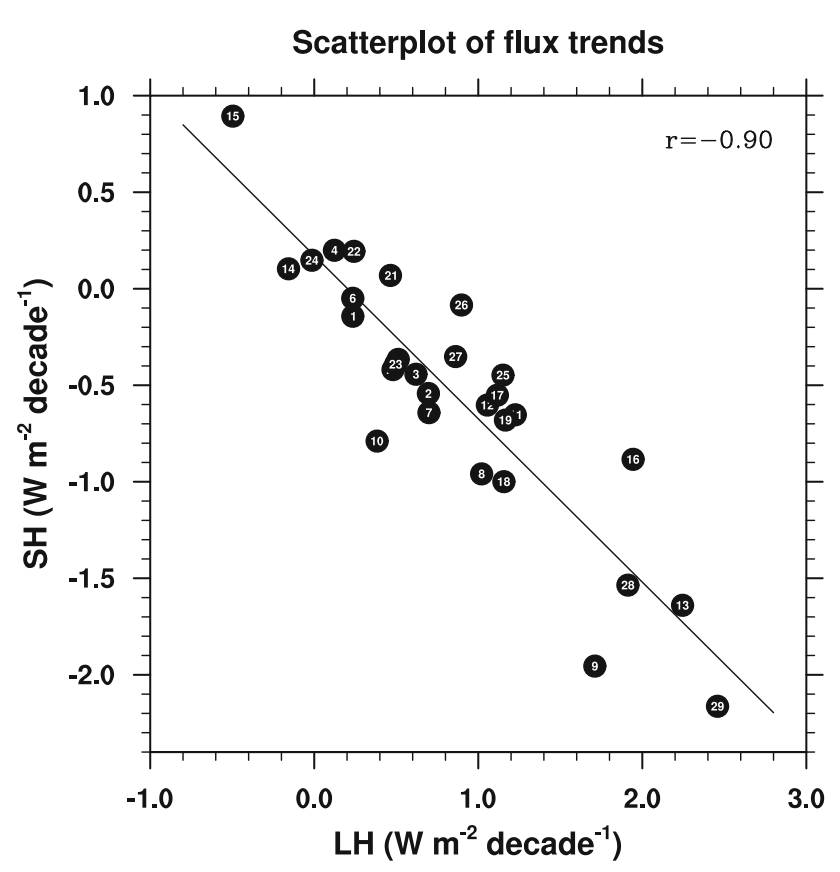

Fig. 6 Scatterplot of the regionally-averaged and annual-mean trend in sensible heat transport against similar trends in latent heat transport in the Peninsula. A least-squares fit regression line is shown as the diagonal. The number of each simulation is also shown

We note that strong $S H$ cooling is consistently seen in all seasons, and is dominant over other cooling trends in 3 out of 4 seasons (Table 3).

For the sake of completeness, we also briefly examine trends in the other two fluxes that typically suppress warming, but are generally much less dominant than $S H$ : surface heat flux $(S F)$, and shortwave flux (SW). The cooling effect of the typical surface heat flux $(S F)$ trend in the Peninsula arises from the fact that the surface generally takes up heat in a warming climate. However, this effect is typically very small (Fig. 3), due to the small heat capacity of the ice-covered surface in the Peninsula. The cooling effect of the typical $S W$ trend results mainly from an increase in cloudiness. We find that $84 \%$ of the simulations exhibit an increase in cloudiness, with the ensemble-mean trend being about $0.28 \%$ decade $^{-1}$ (not shown). This is consistent with the increase in precipitation implied by Fig. 4 and the positive $L H$ trend in the Peninsula.

\section{Links to the SAM}

It has been suggested that during the SAM's positive phase, the Antarctic Peninsula is generally wetter (van den Broeke and van Lipzig 2004; Thomas et al. 2008). It is thus possible that some of the $L H$ increases discussed above are induced by positive SAM trends in the hindcasts. In fact, we find that 10 out of 12 models exhibit positive SAM trends of anthropogenic origin in at least one run (Fig. 7). This is roughly consistent with observations (i.e, Marshall 2003), though as an ensemble, hindcasts underestimate observed SAM trend by about $20 \%$ (Table 6). The underestimation is seen in almost all seasons except for SON, when hindcasts greatly overestimate the observed trend. Nevertheless, the seasonal variation of the observed SAM trend is captured reasonably well by hindcasts. There are large differences in the magnitudes of the trends within different runs of the same models (for example, CGCM3.1(T47), GFDL CM2.0 and MRI CGCM2.3.2), suggesting that the simulated SAM trends are significantly influenced by internal SAM variability. We note that some hindcasts (blue points in Fig. 7) do not account for the depletion of the Southern Hemisphere stratospheric ozone. Yet about $40 \%$ of these hindcasts exhibit anthropogenically-forced positive SAM trends, an indication that the increase in atmospheric greenhouse gas concentration could be inducing at least part of SAM trends in all hindcasts.

To determine how large the $L H$ increases associated with these simulated positive trends might be, we first examine the SAM- $L H$ relationship in the context of internal climate variability. This is done by correlating interannual variations in the SAM index and $L H$ in pre-industrial control experiments. The geographic distribution of the ensemblemean correlation between interannual variations in the SAM index and $L H$ in 12 pre-industrial control experiments is shown in Fig. 8a. The correlation is largely zonally symmetric and generally positive in the Southern Ocean, while negative further north and in the interior of Antarctica. This is consistent with the simulated pattern of precipitation anomalies during the SAM's positive phase (Boer

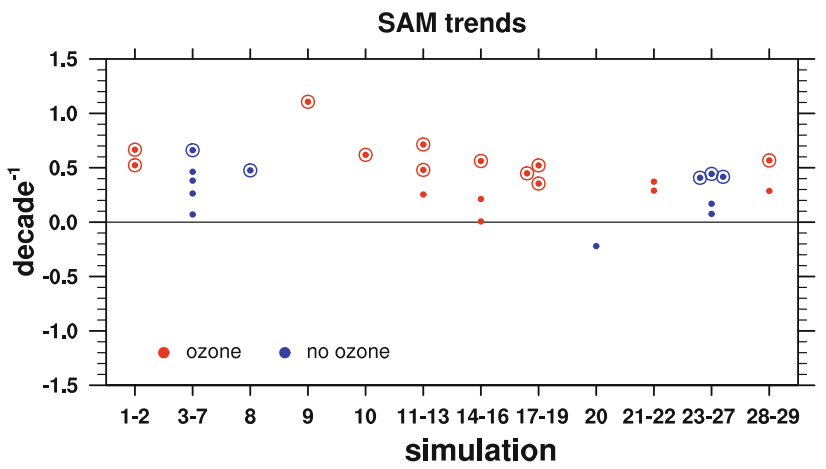

Fig. 7 Annual-mean trends in the SAM index. The same criterion used to determine whether temperature and flux trends have an anthropogenic component is applied to the time series of the SAM index to determine whether they are anthropogenically-forced. Circles represent trends with an anthropogenic component. Models (not) accounting for the depletion of Southern Hemisphere stratospheric ozone are in red (blue) 
Table 6 Observed and simulated SAM trends

\begin{tabular}{llllll}
\hline & Annual & DJF & MAM & JJA & SON \\
\hline Simulations & 0.40 & 0.35 & 0.30 & 0.08 & 0.22 \\
$\begin{array}{l}\text { Observations (after Marshall } \\
\text { 2003) }\end{array}$ & 0.50 & 0.52 & 0.44 & 0.17 & 0.01 \\
\hline
\end{tabular}

Normalized units: decade ${ }^{-1}$

et al. 2001; Karpechko et al. 2009). The correlation is generally positive in the Antarctic Peninsula, especially in the western part, consistent with previous work that the Antarctic Peninsula is generally wetter during the SAM's positive phase.

Given this linkage between the SAM and the Peninsula $L H$, the magnitude of $L H$ trend induced by the SAM trend can be estimated by multiplying the magnitude of the SAM trend with a coefficient representing the magnitude of the $L H$ anomaly induced by a unit change in the SAM index. This coefficient can be estimated based on the pre-industrial experiments by regressing $L H$ time series onto the time series of SAM index. Using this method, we estimate the $L H$ trend induced by the $S A M$ trend at each location for each hindcast. The geographic distribution of the ensemble-mean SAM-induced $L H$ trend is shown in Fig. 8b. Not surprisingly, the pattern of SAM-induced $L H$ trend is similar to the correlation pattern of Fig. 8a. The pattern also bears some resemblance with that of the overall $L H$ trend shown in Fig. 4. Nevertheless, the typical magnitude of the SAM-induced $L H$ trend in most of the Southern Hemisphere mid-to-high latitudes is much smaller than that of the overall $L H$ trend. (Note that the color bars of Figs. 4 and $8 \mathrm{~b}$ are identical.) In the Peninsula, ensemble-mean SAM-induced $L H$ trend is only $0.23 \mathrm{~W} \mathrm{~m}^{-2}$ decade $^{-1}$, less than $1 / 3$ of total $L H$ trend (Table 7 ). This is consistently seen in all seasons. It is also seen in about $2 / 3$ of models. Thus the bulk of $L H$ trend in the Peninsula is generally driven by the intensification of global hydrological cycle rather than the SAM trends. We note that although most simulations exhibit other circulation changes in the Peninsula, these changes are generally inconsistent across simulations. Thus as an ensemble, they contribute little to the pattern of $L H$ trend shown in Fig. 4.

\section{Factors modulating the $L H$ trends}

The regionally-averaged $L H$ trend in the Peninsula differs significantly from simulation to simulation. The annualmean $L H$ trend, for example, ranges from -0.51 to 2.50 $\mathrm{W} \mathrm{m}{ }^{-2}$ decade $^{-1}$ (Fig. 3), causing intermodel differences in the warming in the Peninsula (Fig. 5). Here we (a) LH \& SAM

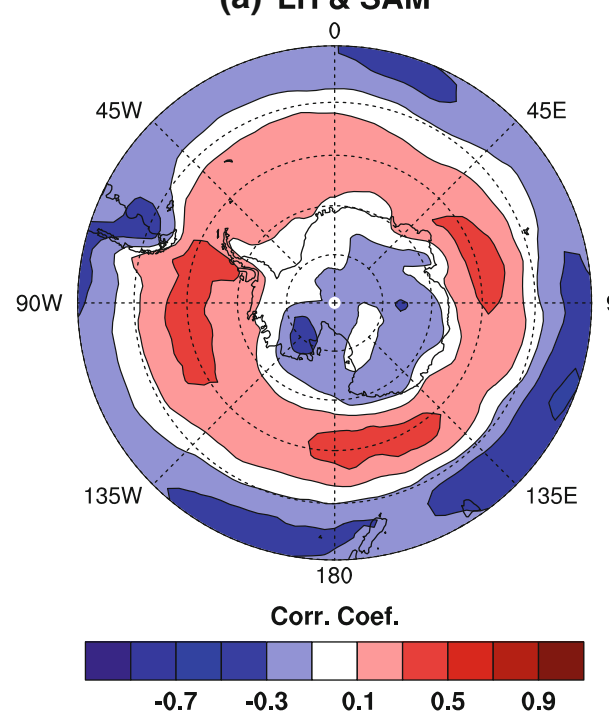

Fig. 8 a Geographic distribution of the ensemble-mean correlation between annual-mean time series of latent heat transport and the SAM index in 12 pre-industrial control experiments. The correlation at each location is first computed for each experiment and then averaged over all experiments to obtain the ensemble-mean. In most of the experiments, thresholds for correlation with the significance level above $95 \%$ is \pm 0.1 . Note that the pattern shown here is similar across experiments. b Geographic distribution of the ensemble- and (b) SAM-induced LH trend

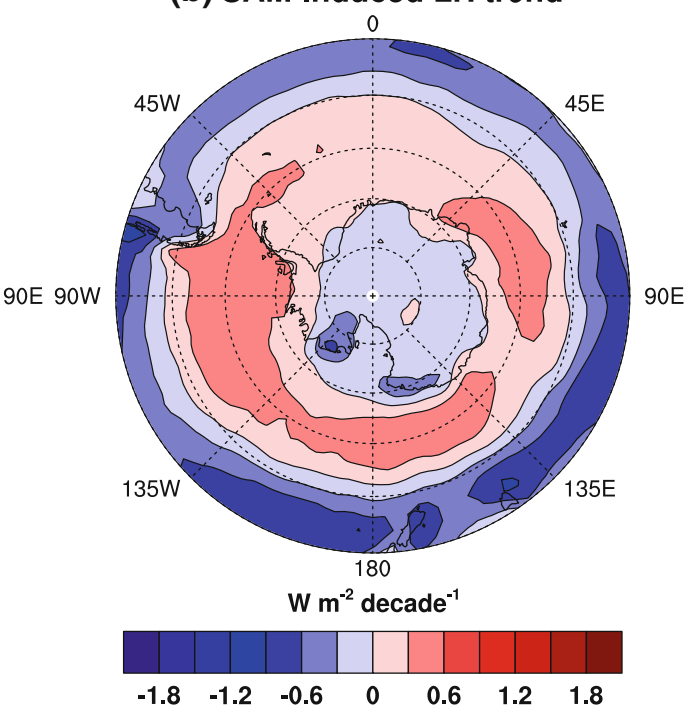

annual-mean latent heat trend induced by the SAM trend. First, a regression coefficient relating the SAM variations to latent heat variations in each pre-industrial control experiment is computed at each location. Then, the regression coefficient is multiplied by the annual-mean SAM trend simulated in the corresponding twentiethcentury hindcasts to obtain the SAM-induced latent heat trend. Finally, the resultant product is averaged over 29 hindcasts to obtain the ensemble-mean 
Table 7 The ensemble-mean SAM-induced latent heat trends (W $\mathrm{m}^{-2}$ decade $^{-1}$ ) in the Antarctic Peninsula

\begin{tabular}{llllll}
\hline & Annual & DJF & MAM & JJA & SON \\
\hline SAM-induced & 0.23 & 0.20 & 0.35 & 0.09 & 0.18 \\
Overall & 0.86 & 0.88 & 1.19 & 0.56 & 0.81 \\
\hline
\end{tabular}

The ensemble-mean of overall latent heat trends in the Peninsula is included here for comparison

determine what causes the $L H$ trend to vary so much. We identify two main factors: (1) oceanic warming to the north of the Peninsula and (2) models' representations of the Peninsula's topography. Simulated SAM trends hardly contribute to differences in the $L H$ trends across hindcasts, consistent with the fact that their contributions to the $L H$ trends are generally very small.

In the mean climate, the water vapor flux is poleward in the mid-to-high latitudes of both hemispheres (Hartmann 1994). It follows that warming and associated increases in atmospheric moisture content in mid-latitudes will lead to increases in poleward water vapor flux to higher latitude locations such as the Antarctic Peninsula. Greater warming ought to lead to larger increases in atmospheric moisture content and proportionately larger increases in poleward water vapor flux. To illustrate how this process is manifested in the case of the Antarctic Peninsula, we correlate the Peninsula $L H$ trends with temperature trends at every location in the Southern Hemisphere mid-to-high latitudes. As expected, we find that the $L H$ trends are most closely associated with temperature anomalies in an oceanic region a few hundred $\mathrm{km}$ to the north (Fig. 9). Simulations with more warming in a southwest Atlantic region centered roughly on the Falkland Islands tend to have larger $L H$ trends in the Peninsula region. Warming in Southwest Atlantic increases local atmospheric moisture content, and the anomalous water vapor is then transported poleward into the Peninsula by atmosphere motions. This results in more precipitation and $L H$ release as the moister flows are forced up and over the Peninsula. Note that the Southwest Atlantic is also where significant warming is seen in observations (Fig. 1a).

To the extent that the correlations in the Southwest Atlantic in Fig. 9 are less than one, factors other than warming in this region may affect the simulated $L H$ trends in the Peninsula. Because orographically-induced condensation is likely greater in models with higher elevation, the models' representations of mean elevation of the Peninsula may be just such a factor. Fig. 10 shows the mean elevation of the Antarctic Peninsula in the models. It is generally around $400 \mathrm{~m}$, but with a few exceptions. The mean elevation in CSIRO Mk3.5 and CGCM3.1(T47) is only about

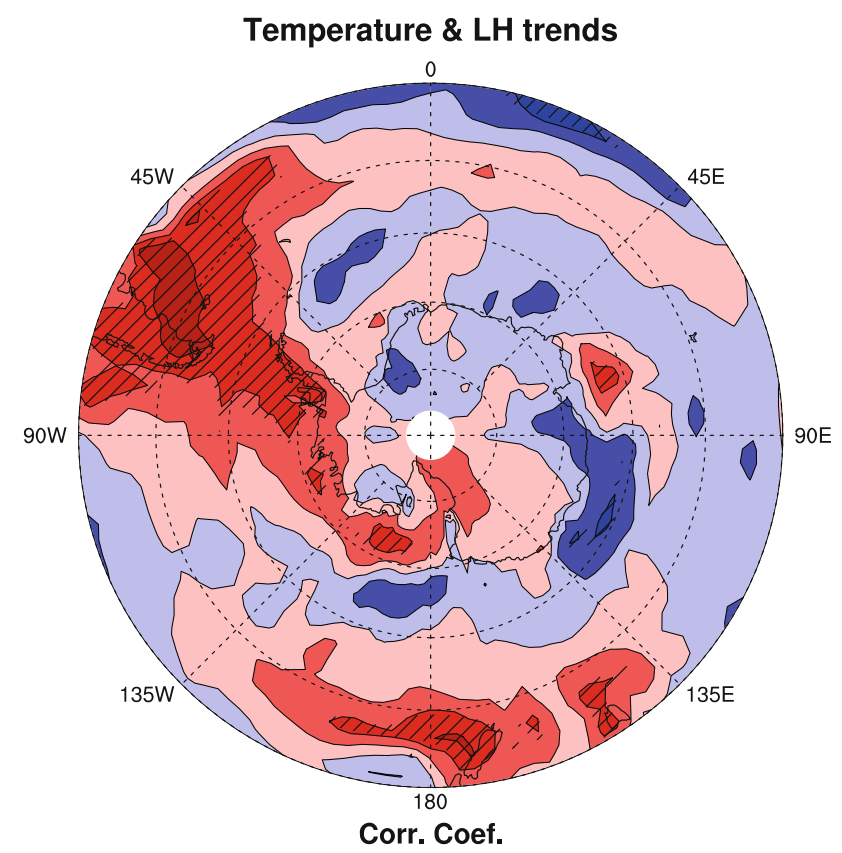

Corr. Coef.

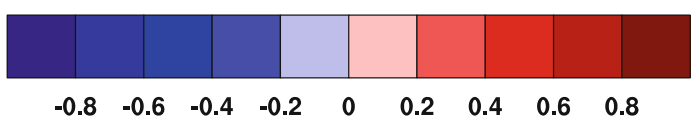

Fig. 9 Geographic distribution of correlation between temperature trend and the regionally-averaged trend in latent heat transport in the Peninsula across 29 hindcasts. Correlation with the significance level above $95 \%$ is shaded

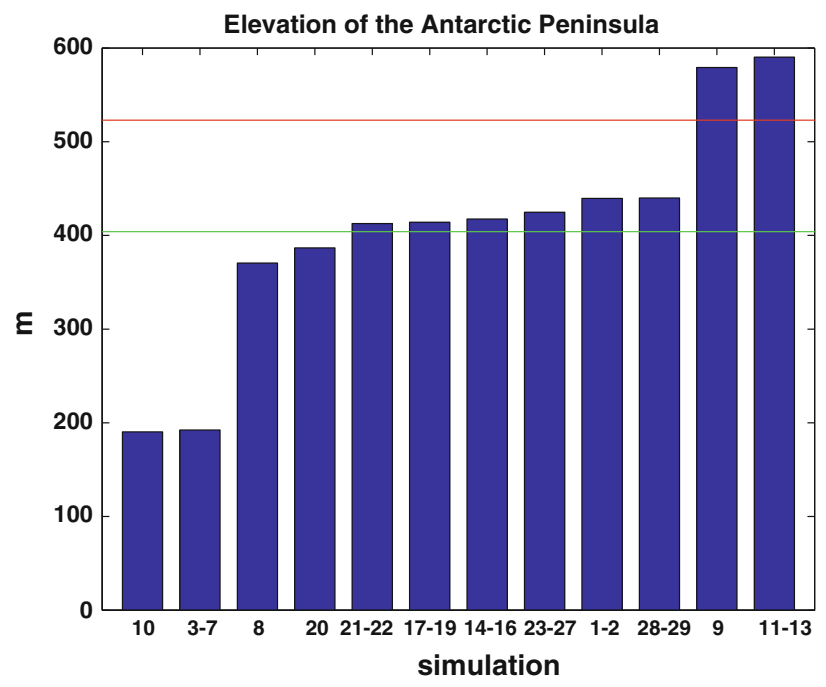

Fig. 10 The mean elevation of the Antarctic Peninsula in 12 models. It is calculated by averaging the elevation of grid points in the Peninsula region with at least $30 \%$ of their areas covered by land. The numbers of simulations (see Table 1) are shown on the $x$-axis. Models are grouped into three categories, "low elevation", "medium elevation" and "high elevation", according to the mean elevation. The "low elevation" models include CSIRO MK3.5 and CGCM3.1(T47), the "high elevation" models include CNRM-CM3 and ECHAM5/MPI-OM and the "medium elevation" models include the rest of the 12 models. The green line represents the ensemblemean and the red line the observed elevation of the Peninsula 
Fig. 11 Geographic

distribution of composite

annual-mean trend in latent heat

transport in a "low elevation",

b "medium elevation" and

c "high elevation" simulations

\section{Composite LH trends}

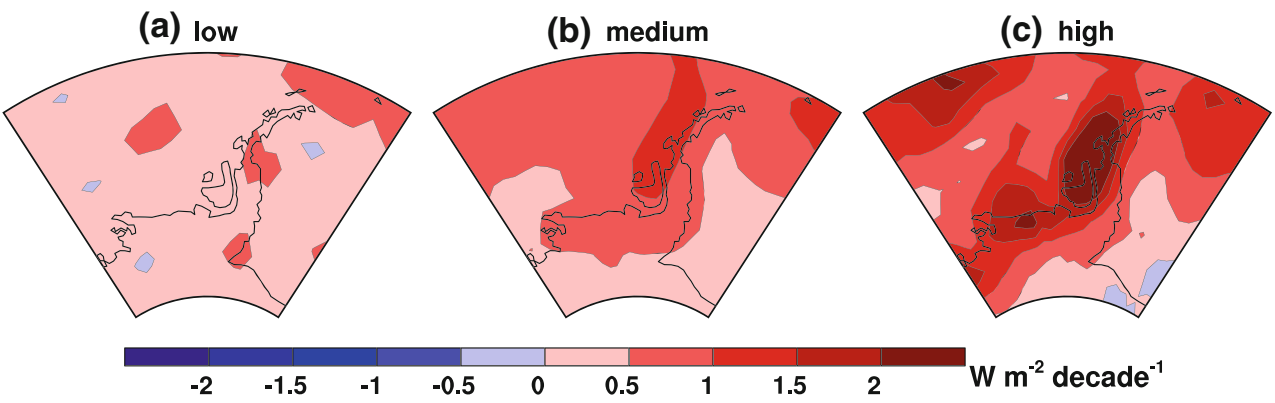

$200 \mathrm{~m}$, while it is nearly $600 \mathrm{~m}$ in CNRM-CM3 and ECHAM5/MPI-OM, much closer to the observed value of $520 \mathrm{~m}$ (Liu et al. 2001). These differences correspond loosely to the model's respective resolutions. For example, CGCM3.1(T47) has the coarsest resolution among all models, while ECHAM5/MPI-OM has the second finest resolution. Somewhat surprisingly, large differences are also seen in models of comparable resolution. For example, CSIRO Mk3.5 and CNRM-CM3 both have medium resolutions, being about $1.9^{\circ} \times 1.9^{\circ}$ and $2.8^{\circ} \times 2.8^{\circ}$, respectively, but the mean elevation in the two models exhibits a threefold difference.

To illustrate how the mean elevation of the Peninsula modulates the $L H$ flux trend, we divide the models into three categories, "low elevation", "medium elevation" and "high elevation", a grouping suggested by the elevation distribution of Fig. 10. Composites of the $L H$ trend are calculated at every location in the Southern Hemisphere mid-to-high latitudes for the three groups (Fig. 11). As the mean elevation increases, $L H$ trends in the Peninsula increase markedly. Regionally-averaged $L H$ trends in the Peninsula are $0.43,0.85$ and $1.57 \mathrm{~W} \mathrm{~m}^{-2}$ decade $^{-1}$ in models with low, medium and high elevation, respectively. Since the mean elevation in the models is generally less than that of the real world, the simulated $L H$ flux increases and the associated warming may be unrealistically weak in the simulations.

\section{Summary and implications}

In this study, we examine simulated warming in the Antarctic Peninsula in 29 twentieth-century hindcasts and demonstrate that increases in latent heat transport into the Peninsula region are its most important cause. Simulated increases are primarily driven by well-documented and well-understood anthropogenic intensification of global hydrological cycle and to lesser extent, positive SAM trends. In the models, the magnitude of the latent heat transport increases may be affected by the temperature increase in the Southwest Atlantic and the resolution of the topography in the Peninsula region.

While this mechanism is very robust in models, its relevance to the observed warming is difficult to assess, due to lack of direct measurements. There are certainly some indications for an increase in latent heat release in the real world. For example, the snow accumulation rate inferred from ice cores drilled in the Peninsula has been increasing since the 1950s (Thomas et al. 2008). It is, nevertheless, impossible to quantify the contribution of this increase to the observed warming. Previous studies have also linked the observed warming to the recent sea ice retreat in the Bellingshausen Sea (King 1994; van den Broeke 2000; Marshall et al. 2002). This mechanism is difficult to assess using the methodology of this study because hindcasts do not simulate a sea ice retreat comparable to observations in an ensemble-mean sense. The extent to which the real sea ice retreat is anthropogenically-forced and is causing the observed warming of the Antarctic Peninsula is unclear, and is a topic for future study.

Acknowledgments This work was supported by NSF-0735056. We acknowledge the modeling groups, the Program for Climate Model Diagnosis and Intercomparison (PCMDI) and the WCRP's Working Group on Coupled Modelling (WGCM) for their roles in making available the WCRP CMIP3 multi-model dataset. Support of this dataset is provided by the Office of Science, U.S. Department of Energy. We thank Drs. Andrew Monaghan and William Chapman for their help with the observational data sets, and two anonymous reviewers for their constructive criticisms of our previous manuscript.

\section{Appendix: Information on pre-industrial control experiments}

Some relevant information on pre-industrial control experiments is given in this appendix, including the lengths of the experiments and model drift in surface temperature and latent heat in the Antarctic Peninsula (Table 8). 
Table 8 The magnitude of model drift in regionally-averaged surface temperature $\left(\mathrm{K}\right.$ decade $\left.^{-1}\right)$ and latent heat $\left(\mathrm{W} \mathrm{m}^{-2}\right.$ decade $\left.{ }^{-1}\right)$ in the Antarctic Peninsula in 12 climate models

\begin{tabular}{|c|c|c|c|c|c|c|}
\hline Model & run & Length & Temperature trend & Temperature drift & $L H$ trend & $L H$ drift \\
\hline \multirow[t]{2}{*}{ CCSM3 } & 1 & 500 & 0.166 & 0.026 & 0.323 & 0.053 \\
\hline & 2 & 500 & 0.122 & 0.026 & 0.674 & 0.053 \\
\hline \multirow[t]{5}{*}{ CGCM3.1 (T47) } & 1 & 500 & 0.315 & 0.002 & 0.616 & 0.003 \\
\hline & 2 & 500 & 0.337 & 0.002 & 0.135 & 0.003 \\
\hline & 3 & 500 & 0.234 & 0.002 & 0.544 & 0.003 \\
\hline & 4 & 500 & 0.209 & 0.002 & 0.253 & 0.003 \\
\hline & 5 & 500 & 0.283 & 0.002 & 0.649 & 0.003 \\
\hline CGCM3.1 (T63) & 1 & 350 & 0.305 & 0.005 & 1.001 & 0.001 \\
\hline CNRM-CM3 & 1 & 500 & -0.278 & 0.031 & 1.744 & 0.089 \\
\hline CSIRO Mk3.5 & 1 & 470 & 0.304 & 0.008 & 0.379 & 0.018 \\
\hline \multirow[t]{3}{*}{ ECHAM5/MPI-OM } & 1 & 500 & 0.422 & 0.008 & 1.214 & 0.007 \\
\hline & 2 & 500 & 0.268 & 0.008 & 1.036 & 0.007 \\
\hline & 3 & 500 & 0.505 & 0.008 & 2.289 & 0.007 \\
\hline \multirow[t]{3}{*}{ GFDL CM2.0 } & 1 & 500 & -0.157 & 0.018 & -0.200 & 0.042 \\
\hline & 2 & 500 & 0.187 & 0.018 & -0.514 & 0.042 \\
\hline & 3 & 500 & 0.624 & 0.018 & 1.920 & 0.042 \\
\hline \multirow[t]{3}{*}{ GFDL CM2.1 } & 1 & 500 & 0.384 & 0.021 & 1.155 & 0.037 \\
\hline & 2 & 500 & 0.163 & 0.021 & 1.196 & 0.037 \\
\hline & 3 & 500 & 0.214 & 0.021 & 1.118 & 0.037 \\
\hline IPSL CM4 & 1 & 500 & 0.369 & 0.002 & 0.930 & 0.016 \\
\hline \multirow[t]{2}{*}{ MIROC3.2 (medres) } & 2 & 500 & 0.018 & 0.004 & 0.486 & 0.001 \\
\hline & 3 & 500 & -0.020 & 0.004 & 0.245 & 0.001 \\
\hline \multirow[t]{5}{*}{ MRI CGCM2.3.2 } & 1 & 350 & 0.154 & 0.001 & 0.455 & 0.011 \\
\hline & 2 & 350 & 0.054 & 0.001 & -0.068 & 0.011 \\
\hline & 3 & 350 & 0.253 & 0.001 & 1.177 & 0.011 \\
\hline & 4 & 350 & 0.274 & 0.001 & 0.889 & 0.011 \\
\hline & 5 & 350 & 0.292 & 0.001 & 0.835 & 0.011 \\
\hline \multirow[t]{2}{*}{ UKMO HadCM3 } & 1 & 341 & 0.338 & 0.001 & 1.946 & 0.012 \\
\hline & 2 & 341 & 0.289 & 0.001 & 2.495 & 0.012 \\
\hline
\end{tabular}

It is computed based on pre-industrial control experiments. Simulated temperature and latent heat trends in 29 twentieth-century hindcasts are included for comparison. The lengths of the pre-industrial control experiments are also included. Assuming the magnitude of model drift is comparable in hindcasts and their corresponding pre-industrial control experiments, we find that model drift in temperature and latent heat is between one and three orders of magnitude smaller than climate trends in almost all hindcasts. Note that only one pre-industrial control experiment is available for each model. The run numbers shown in the table refer to twentieth-century hindcasts only

\section{References}

Alexeev VA, Langen PL, Bates JR (2005) Polar amplification of surface warming on an aquaplanet in "ghost forcing" experiments without sea ice feedbacks. Clim Dyn 24:655-666

Arblaster JM, Meehl GA (2006) Contributions of external forcings to Southern Annular Mode trends. J Clim 19:2896-2905

Boer GJ, Fourest S, Yu B (2001) The signature of the annular modes in the moisture budget. J Clim 14:3655-3665

Cai M, Lu JH (2007) Dynamical greenhouse-plus feedback and polar warming amplification. Part II: Meridional and vertical asymmetries of the global warming. Clim Dyn 29:375-391, doi: 10.1007/s00382-007-0238-9

Cai W, Cowan T (2007) Trends in Southern Hemisphere circulation in IPCC AR4 models over 1950-99: Ozone depletion versus greenhouse forcing. J Clim 20:681-693
Chapman W, Walsh JE (2007) A synthesis of Antarctic temperature. J Clim 20:4096-4117

Comiso JC (2000) Variability and trends in Antarctic surface temperatures from in situ and satellite infrared measurements. J Clim 13:1674-1696

Cook AJ, Fox AJ, Vaughan DG, Ferrigno JG (2005) Retreating glacier fronts on the Antarctic Peninsula over the past halfcentury. Science 308:541-544

Forster P, Ramaswamy V, Artaxo P, Berntsen T, Betts R, Fahey DW, Haywood J, Lean J, Lowe DC, Myhre G, Nganga J, Prinn R, Raga G, Schulz M, Van Dorland R (2007) Changes in Atmospheric Constituents and in Radiative Forcing. In: Solomon S, Qin D, Manning M, Chen Z, Marquis M, Averyt KB, Tignor M, Miller HL (eds) Climate change 2007: the physical science basis. Contribution of working group I to the fourth assessment report of the intergovernmental panel on climate change. Cambridge University Press, Cambridge 
Galewsky J (2008) Orographic clouds in terrain-blocked flows: an idealized modeling study. J Atmos Sci 65:3460-3478

Gillett NP, Thompson DWJ (2003) Simulation of recent Southern Hemisphere climate change. Science 302:273-275

Gillett NP, Stone DA, Stott PA, Nozawa T, Karpechko AY, Hegerl GC, Wehner MF, Jones PD (2008) Attribution of polar warming to human influence. Nat Geosci 1:750-754

Gong D, Wang S (1999) Definition of Antarctic oscillation index. Geophys Res Lett 26:459-462

Hartmann D (1994) Atmospheric general circulation and climate. In: Global physical climatology. Academic Press, London, pp 136-170

Held IM, Soden BJ (2006) Robust response of the hydrological cycle to global warming. J Clim 19:5686-5699

Hughes M, Hall A, Fovell RG (2009) Blocking in areas of complex topography, and its influence on rainfall distribution. J Atmos Sci 66:508-518, doi:10.1175/2008JAS2689.1

Jiang Q (2003) Moist dynamics and orographic precipitation. Tellus 55:301316, doi:10.1034/j.1600-0870.2003.00,025.x

Karpechko AY, Gillett NP, Marshall GJ, Screen JA (2009) Climate impacts of the southern annular mode simulated by the CMIP3 models. J Clim 22:375-3768

King JC (1994) Recent climate variability in the vicinity of the Antarctic Peninsula. Int J Climatol 14:357-369

Liu H, Jezek K, Li B, Zhao Z (2001) Radarsat Antarctic mapping project digital elevation model version 2. National Snow and Ice Data Center. Digital media, Boulder

Manabe S, Bryan K, Spelman MJ (1990) Transient response of a global ocean-atmosphere model to a doubling of atmospheric carbon dioxide. J Phys Oceanogr 20:722-749

Marshall GJ (2003) Trends in the Southern Annular Mode from Observations and Reanalyses. J Clim 6:4134-4143

Marshall GJ, Orr A, van Lipzig NPM, King JC (2006) The impact of a changing Southern Hemisphere annular mode on Antarctic Peninsula summer temperatures. J Clim 19:5388-5404

Marshall GJ, Lagun V, Lachlan-Cope TA (2002) Changes in Antarctic Peninsula tropospheric temperatures from 1956-99: a synthesis of observations and reanalysis data. Int $\mathrm{J}$ Climatol 22:291-310

Marshall GJ (2007) Half-century seasonal relationships between the Southern Annular Mode and Antarctic temperatures. Int J Climatol 27:373-383

Monaghan AJ, Bromwich DH (2008) Advances in describing recent antarctic climate variability. Bulletin of American Meteorological Society, pp 1295-1306

Monaghan AJ, Bromwich DH, Chapman W, Comiso JC (2008a) Recent variability and trends of Antarctic near-surface temperature. J Geophys Res-Atmos 113:D04105

Monaghan AJ, Bromwich DH, Schneider DP (2008b) Twentieth century Antarctic air temperature and snowfall simulations by IPCC climate models. Geophys Res Lett 35:L07502, doi: 10.1029/2007GL032630

Neiman P, Persson P, Ralph F, Jorgensen D, White A, Kingsmill D (2004) Modification of fronts and precipitation by coastal blocking during an intense landfalling winter storm in Southern
California: observations during CALJET. Mon Wea Rev 132:242-273

Orr A, Marshall GJ, Hunt JCR, Sommeria J, Wang CG, van Lipzig NPM, Cresswell D, King JC (2008) Characteristics of summer airflow over the Antarctic Peninsula in response to recent strengthening of westerly circumpolar winds. J Atmos Sci 65:1396-1413

Russell JL, Stouffer RJ, Dixon KW (2006) Intercomparison of the Southern Ocean circulations in IPCC coupled model control simulations. J Clim 19:4560-4575

Shepherd A, Wingham D, Payne T, Skvarca P (2003) Larsen ice shelf has progressively thinned. Science 302:856-859

Steig EJ, Schneider DP, Rutherford SD, Mann ME, Comiso JC, Shindell DT (2009) Warming of the Antarctic ice-sheet surface since the 1957 International Geophysical Year. Nature 457:459-463

Thomas ER, Marshall GJ, McConnell JR (2008) A doubling in snow accumulation in the western Antarctic Peninsula since 1850. Geophys Res Lett 35:L01,706, doi:10.1029/2007GL032,529

Thompson DWJ, Solomon S (2002) Interpretation of recent Southern Hemisphere climate change. Science 296:895-899

Thompson DWJ, Wallace JM (2000) Annular modes in the extratropical circulation. Part I: month-to-month variability. J Clim 13:1000-1016

Turner J, Colwell SR, Marshall GJ, Lachlan-Cope TA, Carleton AM, Jones PD, Lagun V, Reide PA, Iagovkinaf S (2004) The SCAR READER project: towards a high-quality database of mean Antarctic meteorological observations. J Clim 17:2890-2898

Turner J, Colwell SR, Marshall GJ, Lachlan-Cope TA, Carleton AM, Jones PD, Lagun V, Reide PA, Iagovkinaf S (2005) Antarctic climate change during the last 50 years. Int $\mathrm{J}$ Climatol 25:279-294

Turner J, Lachlan-Cope TA, Colwell S, Marshall GJ, Connolley WM (2006) Significant warming of the Antarctic winter troposphere. Science 311:1914-1917

Turner J, Overland JE, Walsh JE (2007) An Arctic and Antarctic perspective on recent climate change. Int $\mathrm{J}$ Climatol 27(3):277-293

van den Broeke MR(2000) On the interpretation of Antarctic temperature trends. J Clim 13:3885-3889

van den Broeke MR, van Lipzig NPM (2004) Changes in Antarctic temperature, wind and precipitation in response to the Antarctic Oscillation. Ann Glaciol 39:119-126

van Lipzig NPM, Marshall GJ, Orr A and King JC (2008) The relationship between the Southern Hemisphere annular mode and Antarctic Peninsula summer temperatures: analysis of a highresolution model climatology. J Clim 21:1649-1668

Vaughan DG, Doake CSM (1996) Recent atmospheric warming and retreat of ice shelves on the Antarctic Peninsular. Nature 379:328-331

Vaughan DG, Marshall GJ, Connolley WM, Parkinson C, Mulvaney R, Hodgson DA, King JC, Pudsey CJ, Turner J (2003) Recent rapid regional climate warming on the Antarctic Peninsula. Clim Change 60:243-274, doi:10.1023/A:1026021217,991 